\title{
Correction to: Assessment of Geotechnical Properties and Determination of Shear Strength Parameters
}

\author{
Benyamin Ghoreishi • Mohammad Khaleghi Esfahani • Nargess Alizadeh Lushabi • \\ Omid Amini - Iman Aghamolaie • Nik Alif Amri Nik Hashim • Seyed Mehdi Seyed Alizadeh
}

Published online: 25 August 2020

(C) Springer Nature Switzerland AG 2020

\section{Correction to: \\ Geotech Geol Eng \\ https://doi.org/10.1007/s10706-020-01504-1}

In the original publication of the article, the first author name was incorrectly published as "Benyamin
Ghoreishii". However, the correct name is "Benyamin Ghoreishi". The original article has been corrected.

Publisher's Note Springer Nature remains neutral with regard to jurisdictional claims in published maps and institutional affiliations.
The original article can be found online at https:// doi.org/10.1007/s10706-020-01504-1.

\section{B. Ghoreishi}

School of Railway Engineering, Iran University of

Science and Technology, Tehran, Iran

M. K. Esfahani ( $\square)$

M.Sc. Graduate of Engineering Geology, University of Isfahan, Isfahan, Iran

e-mail: M.khaleghi88@yahoo.com

\section{N. A. Lushabi}

M.Sc. Graduate of Structural Geology, Shahrood

University of Technology, Shahrood, Iran

\section{O. Amini}

Faculty of Civil and Surveying Engineering, Graduate

University of Advanced Technology, Kerman, Iran

I. Aghamolaie

Ph.D. Department of Geology, Faculty of Science, Shahid

Bahonar University, Kerman, Iran

\section{N. A. A. N. Hashim}

Faculty of Hospitality, Tourism and Wellness, University Malaysia Kelantan, Kelantan, Malaysia

\section{S. M. S. Alizadeh}

Petroleum Engineering Department, Australian College of Kuwait, West Mishref, Kuwait 